\section{KІБЕРНЕТИКА та КОМП'ЮТЕРН ТЕХНОЛОГІЇ}

Створення алгоритмів для розв'язування задач комбінаторної оптимізаиії для гібридних квантово-напівпровідникових обчислювальних комплексів дозволяє прискорити отримання результатів та отримати більи точні розв'язки. Розглянуто універсальні і спеціальні підходи до обчислень на квантових комп'ютерах. Наведено приклад розв'язування задачі пошуку найбільшої незалежноі множини на квантових комп'ютерах IBM $i$ D-wave, які доступні через хмарні сервіси.

Ключові слова: квантовий комп'ютер, комбінаторна оптимізація, найбільша незалежна множина графу.

(C) В.Ю. Корольов, О.М. Ходзінський, 2020
УДК 004.4:519.684

DOI:10.34229/2707-451X.20.2.1

В.Ю. КОРОЛЬОВ, О.М. ХОДЗІНСЬКИЙ

\section{РОЗВ'ЯЗУВАННЯ ЗАДАЧ КОМБІНАТОРНОЇ ОПТИМІЗАЦІї НА КВАНТОВИХ КОМП'ЮТЕРАХ}

Вступ. Сучасні квантові комп'ютери на декілька порядків продуктивніше виконують низку широко використовуваних алгоритмів у порівнянні з сучасними електронними комп'ютерними системами, що побудовані на напівпровідникових логічних вентилях.

Тому розробка алгоритмічно-програмного забезпечення для квантових комп'ютерів - це актуальна наукова і прикладна проблема. Уряди розвинутих країн та міжнародні корпорації інвестують значні фінансові ресурси у створення квантових комп'ютерів для прискорення обчислень прикладних задач та активно їх впроваджують.

На момент написання статті вже існує ряд квантових комп'ютерних прототипів. У IBM є декілька квантових комп'ютерів 3 1-15 кубітами, які доступні для публічного використання через хмарні сервіси, та квантовий комп'ютер 3 приблизно 50 кубітами для платного доступу.

y Google є квантовий процесор, що містить 72 кубіти, названий "Bristlecone", Intel має квантовий комп’ютер "Horse Ridge" з 128 кубітами. Нові компанії D-Wave (2048 кубіт) та Rigetti (19 кубіт) надають платний доступ і обмежений у часі вільний доступ до квантових обчислень. Компанією Amazon на платній основі надається платний доступ до квантових комп'ютерів: D-Wave, Rigetti, IonQ на базі хмарних сервісів.

Високорівневе квантове програмування все ще $\epsilon$ новим предметом дослідження, теорія алгоритмів для якого знаходиться в стадії розробки, відсутня також верифікація програмних бібліотек для багатьох базових алгоритмів. Тому актуальним завданням для квантової комп’ютерної математики є розробка загальної термінології, методів і алгоритмічних інструментів для різних мов програмування додатків та способів застосування. 


\section{Загальна схема операцій для квантових обчислень}

Квантова суперпозиція - це одночасне існування станів кубіта, які не можуть бути реалізовані одночасно з класичної точки зору. Виконання квантових обчислень базується на послідовності 3 трьох макро операцій (Рис. 1) [1-3]:

- створення квантової суперпозиції;

- виконання обчислень у суперпозиції та перетворень кубітів;

- зменшення шуму вимірювання і зчитування даних.

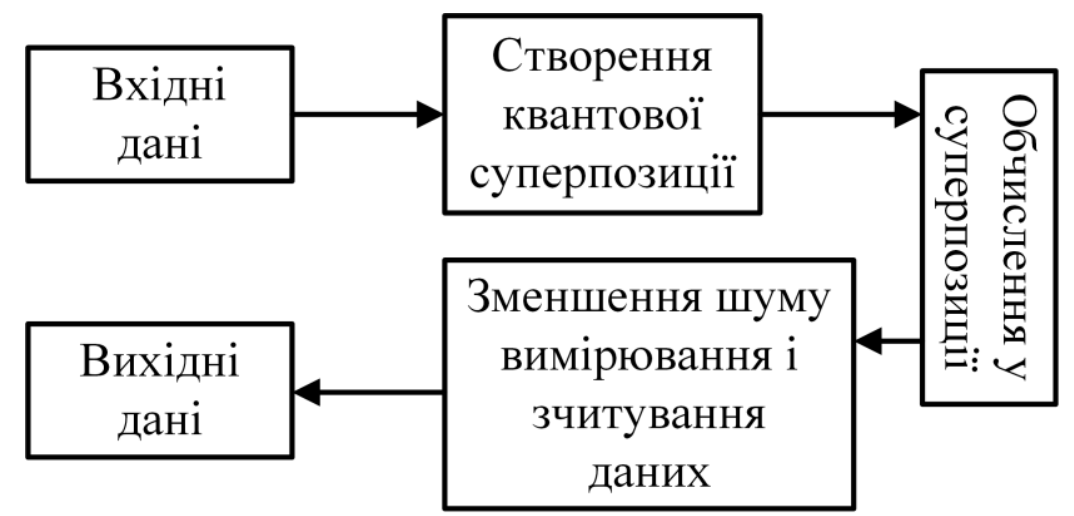

РИС. 1. Послідовність операцій для квантових обчислень

У всіх квантових алгоритмах присутні наступні етапи:

1) підготовка суперпозиції вхідних даних для обчислення функції;

2) застосування самої функції (алгоритма або квантового оракула);

3) перетворення отриманих станів таким чином, щоб ймовірність потрібного для нас результату була близька до одиниці (калібрування обладнання, зменшення шуму і багатократні запуски процесу розв'язування задачі).

Слід зазначити, що для порівняння квантових комп'ютерів різної структури та фізичними принципами роботи немає єдиної методики. Кількість кубітів може здатися найважливішим критерієм, але важливою є також кількість зв'язків між ними (Рис. 2), оскільки кубіти не підключають до спільної шини передачі даних, як в електронних обчислювальних машинах (ЕОМ). Одна з головних труднощів при побудові квантових комп'ютерів - це збереження квантових станів якомога довше, що найчастіше досягається низькими температурами та контролюванням часу виконання обчислень. Найменше порушення фізичного стану системи може зруйнувати квантові стани, і тоді квантові обчислення матимуть помилки, які потрібно буде виправляти.
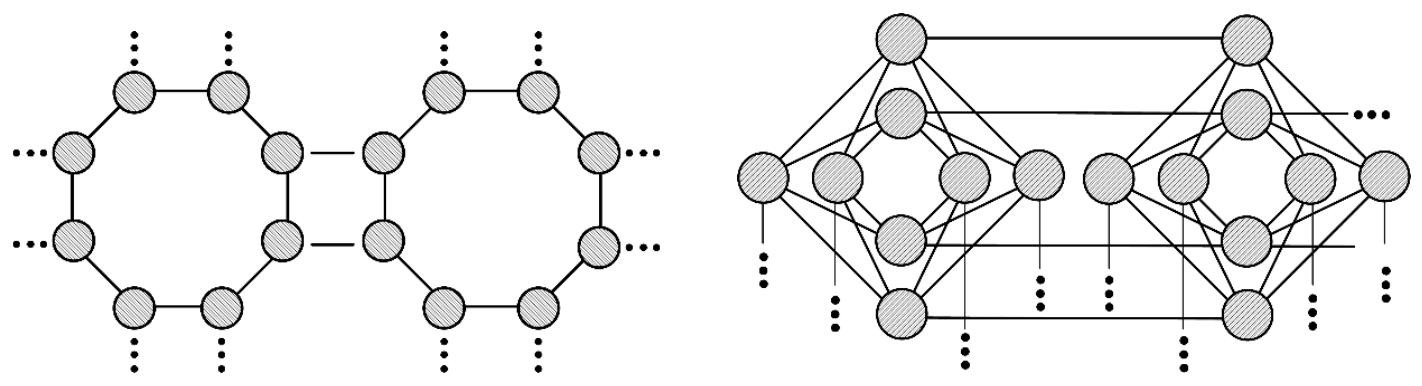

РИС. 2. Структури з’єднання кубітів для квантових процесорів фipм Rigetti та D-wave 
Зв'язки між кубітами з точки зору комп'ютерної математики означають можливість передачі даних між ними або застосування до їх станів квантових вентилів для виконання операцій.

Розв'язування задач комбінаторної оптимізації за допомогою квантових комп'ютерів

Обсяг обчислень, необхідних для розв'язування NP-складних задач оптимізації $[4-8,11]$, швидко зростає зі збільшенням розмірності задачі. Такі задачі неможливо розв'язувати методом прямого перебору, навіть 3 необмеженими обчислювальними ресурсами. Для розв'язування NPскладних задач оптимізації застосовуються наближені алгоритми, зокрема, метаевристики $[12,13]$. Застосування квантових обчислень дозволяє прискорити розв'язування NP-складних задач оптимізації та отримати рішення підвищеної точності.

Сучасні квантові комп'ютери, призначені для комерційного використання, мають від сотні до декількох тисяч кубіт, які об'єднані у групи, що налічують десятки кубіт та мають обмежену кількість зв'язків як між окремими кубітами, так і між їх групами, що утворюють квантовий процесор. Оскільки повністю розв'язувати задачі комбінаторної оптимізації великої розмірності на квантових комп'ютерах на сьогоднішній день неможливо, використовують змішані обчислення. Тобто підготовку даних, керування чергою задач та виведення результатів виконують класичні ЕОМ, а розв'язування NP-складних задач виконують квантові комп'ютери.

До побудови алгоритмів розв'язування задач комбінаторної оптимізації на квантових комп'ютерах застосовуються два підходи [1-3]:

- універсальні квантові обчислення, тобто побудова послідовностей арифметико-логічних операцій для кубітів квантового комп’ютера;

- використання фізичних квантових процесів, орієнтованих на досягнення низькоенергетичного стану для пошуку мінімуму, наприклад, квантовий відпал.

На сьогоднішній день перший підхід використовується в основному для підготовки даних перед застосуванням алгоритмів, які побудовані на другому підході в силу малого обсягу оперативної пам'яті сучасних квантових комп'ютерів. Наведемо приклад універсальних квантових обчислень - схему виконання операції складання двох кубіт а1 i b1 для квантового комп'ютера [9] (Рис. 3 і Табл. 1). 3 лівого краю схеми позначено чотири кубіти та два біти в які записується результат обчислень. Тобто виконується складання двійкових чисел $1_{2}+1_{2}=10_{2} .|0\rangle$ та $|1\rangle$ на Рис. 3 позначено квантові стани кубітів (бракет нотація $[1,2])$.

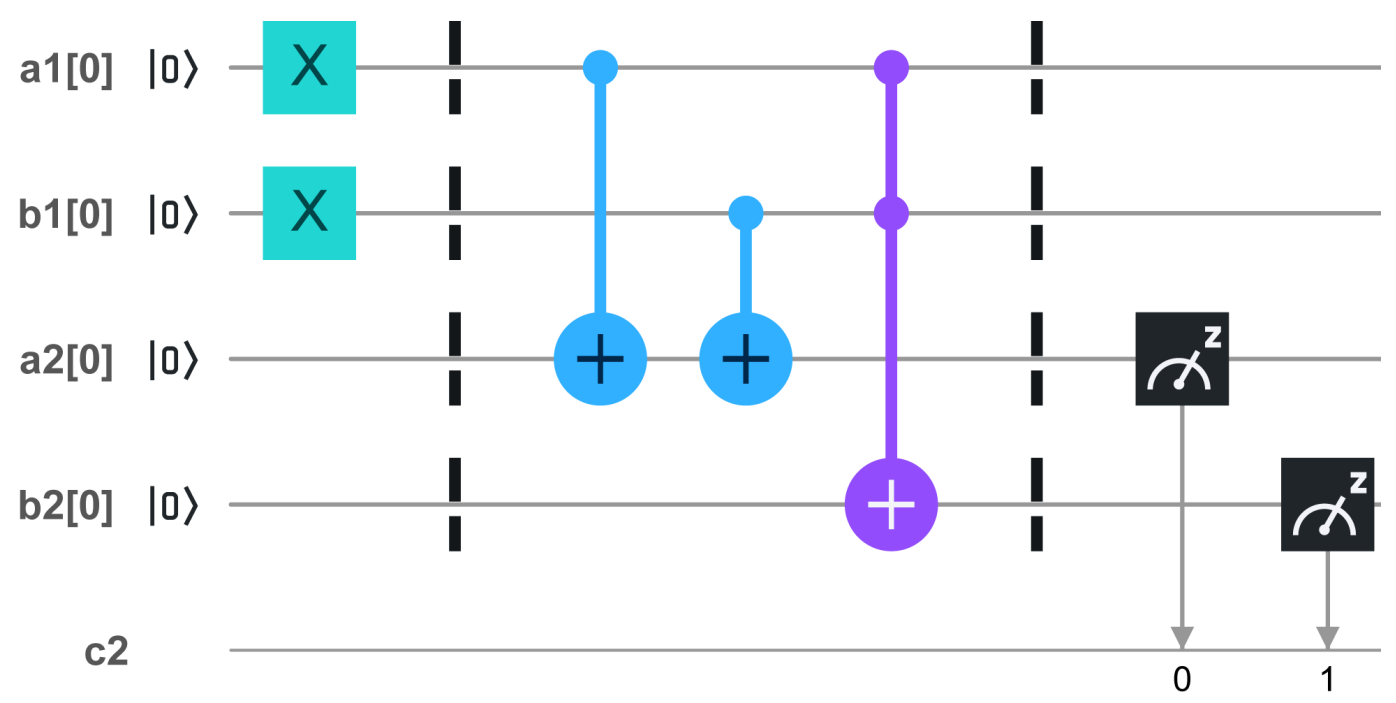

РИС. 3. Квантова схема для виконання складання двох кубіт з переносом розряду 
ТАБЛИЦЯ 1. Опис позначення елементів на квантовій обчислюваній схемі Рис. 3

\begin{tabular}{|c|c|c|}
\hline Назва & Елемент & Опис \\
\hline Toffoli & & $\begin{array}{l}\text { Вентиль Toffoli, має два кубіти "керування" та одну "ціль", } \\
\text { застосовується до цілі лише тоді, коли обидва елементи керу- } \\
\text { вання перебувають у стані }|1\rangle\end{array}$ \\
\hline CNOT & & $\begin{array}{l}\text { Діє на пару кубітів, причому один виступає як "керування", а } \\
\text { другий як "ціль". Вентиль виконує операцію "Не" над кубіта- } \\
\text { ми, коли контроль знаходиться в стані }|1\rangle\end{array}$ \\
\hline Pauli X & & $\begin{array}{l}\text { Повертає спін кубіта у протилежному напрямку. Наприклад, } \\
\text { для зміни значення кубіта } 3|1\rangle \text { на }|0\rangle \text { або навпаки }\end{array}$ \\
\hline $\begin{array}{l}\text { Meas- } \\
\text { urement }\end{array}$ & & Вимірює значення кубіта та записує його у біт \\
\hline
\end{tabular}

За допомогою квантових вентилів Pauli X записуються значення кубітів $|1\rangle$ і створюється суперпозиція базових станів, потім виконуються операції додавання кубітів за допомогою вентилів CNOT i Toffoli, отриманий результат вимірюється і записується у класичні біти.

Розв'язування задачі про найбільшу незалежну множину

Постановка задачі. Задано простий неорієнтований граф $G(V, E)$, де $V$ - множина вершин, $E$ - множина ребер, $n$ - кількість вершин, $m$ - кількість ребер, $V=\{1,2, \ldots, n\}$, $E=\left\{\left(u_{1}, v_{1}\right),\left(u_{2}, v_{2}\right), \ldots,\left(u_{m}, v_{m}\right)\right\} ; u_{i}, v_{i} \in V ; i=1, \ldots, m$. Кожній вершині $i$ поставлено у відповідність змінну $x_{i}$, яка може приймати значення 0 або $1: x=\left(x_{1}, \ldots, x_{n}\right), x_{i} \in\{0,1\}$. Задано також функцію $f(x)=\sum_{i=1}^{n} x_{i}$ і обмеження на значення вектора $x=\left(x_{1}, \ldots, x_{n}\right):(i, j) \in E \Rightarrow x_{i}+x_{j} \leq 1$.

Таким чином, задача про найбільшу незалежну множину формулюється так: знайти

за обмежень

$$
\max f(x)=\sum_{i=1}^{n} x_{i}
$$

$$
\begin{gathered}
(i, j) \in E \Rightarrow x_{i}+x_{j} \leq 1 \\
x_{i} \in\{0,1\}, i=1, \ldots, n
\end{gathered}
$$

Алгоритм повного перебору. Ідея алгоритму:

- перебрати всі можливі значення вектора $x$;

- відкинути ті значення $x$, які не задовольняють обмеженням;

- для всіх $x$, що залишилися, обчислити $f(x)$;

- вибрати вектор $x$, для якого значення $f(x)$ максимальне. 
Перебирання всіх можливих значень вектора $x$. Так як змінні $x_{i}$ приймають значення 0 або 1 , то вектор $x$ можна розглядати як ціле невід'ємне число в двійковій системі числення. Найменше таке число 0 , тобто коли всі $x_{i}=0$, найбільше дорівнює $2^{n}-1$, тобто коли всі $x_{i}=1$. Для перебирання всіх двійкових чисел виконується окрема процедура, яка за заданим числом обчислює число на 1 більше за задане.

Наведемо приклади додавання в стовпчик одиниці в двійковій системі числення: $0+1=1$, $5+1=6,39+1=40$.

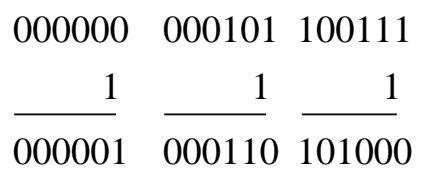

Закономірність тут така: треба рухатись справа наліво по розрядах числа, одиниці замінювати на нулі, перший нуль замінити на одиницю і зупинитись.

Зауваження. Порядок змінних у векторі $x=\left(x_{1}, \ldots, x_{n}\right)$ протилежний порядку розрядів у двійковому числі $x=x_{n} \ldots x_{1}$.

Приклад розв'язків задачі. Вершини максимальної незалежної множини позначені темним кольором (Рис. 4).
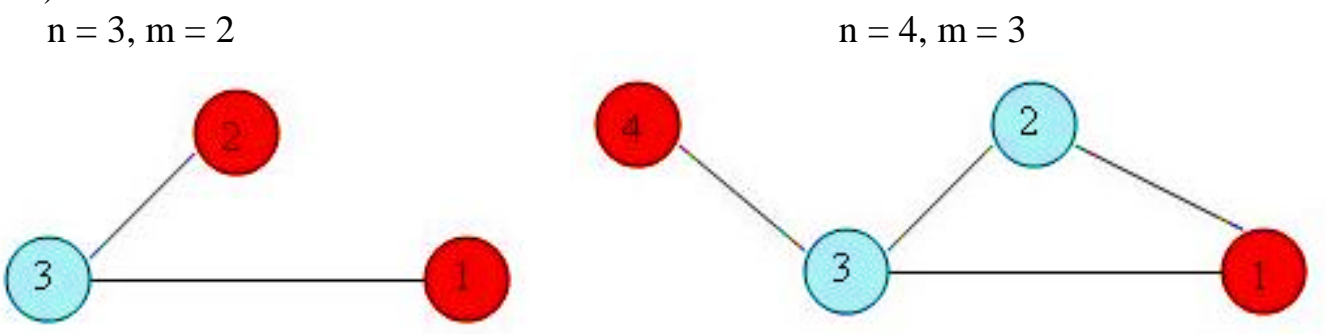

РИС. 4. Приклади розв’язку задачі пошуку максимальної незалежної множини

Ця задача, як і більшість інших у комбінаторній оптимізації - NP-складна [4-8]. У таких випадках проблеми оптимізації швидко стають невирішуваними методами прямого перебору, навіть із великими обчислювальними ресурсами. Розв'язування цього класу задач з великим масштабом при зростанні продуктивності комп'ютерів у відповідності до закономірності Мура потребуватиме декількох століть. Тому до проблем обчислювально складних задач оптимізації зазвичай застосовують евристичні підходи та емпіричні методики. Розробка евристичних алгоритмів може забрати багато часу, щоб отримати задовільні відповіді, крім того вони не гарантують отримання оптимального рішення.

Квантовий відпал - це обчислювальний метод, розроблений для розв'язування NP-складних задач комбінаторної оптимізації. Сучасні квантові відпалювачі розв'язують задачі квадратичної необмеженої бінарної оптимізації (quadratic unconstrained binary optimization - QUBO), також відомі як спінова модель Ізінга. Оскільки задача пошуку незалежної множини - це задача з обмеженнями, то виконується зведення задачі до загальної форми виду:

$$
\min (\text { цільова функиія })+\gamma[\text { обмеження }] \text {. }
$$

Значення $\gamma$ виконується налаштуванням параметрів квантових обчислювачів та перевіряється за допомогою повторювання обчислень. 
Щоб сформулювати задачу для квантового обчислювача, треба побудувати цільову функцію, яка $є$ відображенням фізичного стану системи як функції бінарних змінних, що представляють кубіти. У квантових обчислювачах вузли графу відображають кубітами, а ребра - з'єднаннями між кубітами. Для більшості випадків чим нижчий енергетичний стан квантової системи, що відображає цільову функцію, тим розв'язок задачі ближче до оптимального.

Розглянемо розв'язування задачі про найбільшу незалежну множину на універсальному квантовому комп'ютері фірми IBM [9] та спеціалізованому квантовому обчислювальному пристрої фірми D-wave [10] для розв'язування задач мінімізації методом квантового відпалу. Виробниками квантових комп'ютерів розроблено програмні бібліотеки для мови програмування Python, які дозволяють отримати розв'язок задачі пошуку найбільшої незалежної множини для графу. Щоб отримати розв'язок задачі треба подати опис графа на вхід програми та обрати квантовий комп'ютер з доступних онлайн та встановити параметри обчислень, наприклад, кількість запусків задачі. Результати експериментів подані у Табл. 2. У даній таблиці наведені значення цільової функції, варіанти розв'язку задачі - незалежні вузли та значення енергії системи для відповідних варіантів.

ТАБЛИЦЯ 2. Результати розв’язування задачі про найбільшу незалежну множину на квантових комп’ютерах

\begin{tabular}{|l|lllc|}
\hline IBM & D-wave & & \\
\hline energy: -1.5 & Set 0 & Set 1 & Energy & Cut Size \\
max-cut objective: -4.0 & {$[3,4]$} & {$[1,2]$} & -3.0 & 4 \\
solution: [0. 1. 0. 1.] & {$[1,2]$} & {$[3,4]$} & -3.0 & 4 \\
solution objective: 4.0 & {$[1,3]$} & {$[2,4]$} & -1.0 & 3 \\
& {$[1,4]$} & {$[2,3]$} & -1.0 & 3 \\
& {$[2,3]$} & {$[1,4]$} & -1.0 & 3 \\
& & & &
\end{tabular}

Результати. У роботі запропоновано принципи класифікації алгоритмів розв'язання задач 3 точки зору квантової комп'ютерної математики. Показано, що кількість і сила зв'язків між кубітами впливає на розмірність задач, розв'язуваних алгоритмами квантової комп'ютерної математики. Запропоновано розглядати два підходи до обчислення задач комбінаторної оптимізації на квантових комп'ютерах: універсальний, за допомогою квантових вентилів, і спеціалізований, на базі параметризації фізичних процесів. Наведено приклад побудови напівсумматора для двох кубітів квантового процесора фірми IBM і приклад вирішення задачі пошуку максимальної незалежної множини для квантових комп'ютерів фірм IBM i D-wave.

Висновки. Нині є обмежений у часі онлайн-доступ до квантових комп’ютерів $315-2048$ кубітами, розроблено візуальні інтерфейси виконання і програмні бібліотеки, що суттєво спрощують дослідження розроблених додатків. Щорічний вихід нових зразків квантових процесорів 3 подвоє- 
ною кількістю кубітів та багатократним збільшенням кількості зв'язків між ними порівняно 3 попередніми зразками дає підстави припускати, що для квантових обчислювачів може існувати аналог закономірності Мура для електронних (напівпровідникових) обчислювальних машин. Програмування квантових комп'ютерів виконується переважно на мові Python $з$ бібліотеками від різних виробників, рідше на Асемблері IBM, Google C++, JavaScript, Q\# Microsoft та у візуальному середовищі збирання квантових обчислюваних схем для виконання простих операцій (Рис. 2).

На сьогоднішній день немає домінуючої квантової комп'ютерної архітектури, крім того, квантові комп'ютери будують на різних фізичних принципах, що впливає на ефективність високорівневих алгоритмів. Між класичною двійковою булевою логікою та квантовою логікою є суттєві відмінності, тому методи розробки програмних бібліотек, що використовуються сьогодні, можуть бути застосовані лише частково до квантових комп'ютерів.

Порівняння різних квантових комп'ютерів $€$ нетривіальною задачею. Кількість кубітів $є$ найважливішим критерієм, але кількість зв'язків між кубітами також суттєво впливає на продуктивність обчислень. Однією з головних труднощів при побудові квантових комп'ютерів є збереження квантових станів якомога довше. Найменше порушення може зруйнувати квантові стани, і тому квантові обчислення можуть мати помилки, які потрібно виправляти.

Сучасні пристрої, що апаратно-програмно виконують квантовий відпал, розроблені для вирішення складних проблем оптимізації, втім вони мають апаратні обмеження на кількість кубітів та складність їх з'єднання.

Обчислювально складні задачі комбінаторної оптимізації є нерозв'язними навіть для потужних сучасних обчислювальних систем i, ймовірно, залишаться такими, навіть враховуючи зростання обчислювальної потужності у відповідності до закономірності Мура. Крім того слід додати, що розмірність сучасних проблем зростає експоненціально, а технології виробництва напівпровідникових комп'ютерів вже наблизились до фізичних меж.

Квантові комп'ютери, зокрема квантові відпалювачі, пропонують нову парадигму, яка допоможе подолати ці проблеми. Однак сучасне покоління обладнання для забезпечення якості розв'язків ще має багато обмежень, $\mathrm{i}$, отже, найбільш перспективні результати виходять із неоднорідного квантово-класичного підходу. У роботі подано результати за цими напрямками, з ілюстрацією вирішення реальної задачі. Це дослідження є цінним не тільки для уточнення розв'язків цієї конкретної задачі, але й як інструмент для вирішення інших трудомістких задач оптимізації у багатьох різних контекстах.

Отримати переваги від застосування квантових обчислень для вирішення прикладних проблем неможливо на базі подальшої розробки квантової комп'ютерної математики та розробки відповідного алгоритмічно-програмного забезпечення.

\section{Список літератури}

1. Moran C.C. Mastering Quantum Computing with IBM QX. Birmingham: Packt, 2019.

2. Vos J. Quantum Computing for Developers: A Java-based introduction. New York: Manning, 2020.

3. Johnston E.R., Harrigan N., Gimeno-Segovia M. Programming Quantum Computers. Essential Algorithms and Code Samples. Sebastopol: O’Reilly, 2019.

4. Корольов В.Ю. Маршрутизація ланки крилатих ракет багаторазового використання. Управляюшие системы $u$ машины. 2019. 2. С. 16 - 24. https://doi.org/10.15407/usim.2019.02.016

5. Гуляницький Л.Ф., Корольов В.Ю., Огурцов М.І., Ходзінський О.М. Проблема маршрутизації груп БПЛА в задачах пошуку і моніторингу. Компьютерная математика. 2018. 2. С. 38 - 47. http://dspace.nbuv.gov.ua/handle/123456789/161884

6. Корольов В.Ю., Ходзінський О.М. Тополого-комбінаторна модель побудови мереж для транспортних засобів. Компьютерна математика. 2018. 1. С. 61 - 67. http://dspace.nbuv.gov.ua/handle/123456789/161850 
7. Корольов В.Ю., Огурцов М.І. Транспортно-комунікаційна задача для груп безпілотних апаратів. Математичні машини і системи. 2017. 1. C. 82 - 89. http://dspace.nbuv.gov.ua/handle/123456789/117508

8. Корольов В.Ю., Поліновський В.В., Огурцов М.І. Моделювання мереж зв'язку рухомих дистанційно керованих систем на базі HLA. Вісник Хмельницького національного університету. 2017. 1 (245). С. 160 - 165. http://nbuv.gov.ua/j-pdf/Vchnu_tekh_2017_1_33.pdf

9. Asfaw A. Learn Quantum Computation using Qiskit. New York: IBM. 2019. URL: https://qiskit.org/textbook/chapplications/qaoa.html (дата звернення: 15.03.2020).

10. Maximum Cut. URL: https://github.com/dwave-examples/maximum-cut (дата звернення: 15.03.2020).

11. Гэри М., Джонсон Д. Вычислительные машины и труднорешаемые задачи. Москва: Мир, 1982. 416 с.

12. Talbi E.-G. Metaheuristics: from design to implementation. New Jersey: Wiley \& Sons, 2009. https://doi.org/10.1002/9780470496916

13. Гуляницький Л.Ф., Мулеса О.Ю. Прикладні методи комбінаторної оптимізації. Київ: Видавничо-поліграфічний центр "Київський університет", 2016. 142 с.

Одержано 03.04.2020

Корольов Вячеслав Юрійович,

кандидат технічних наук, старший науковий співробітник

Інституту кібернетики імені В.М. Глушкова НАН України, Київ,

https://orcid.org/0000-0003-1143-5846

Ходзінський Олександр Миколайович,

кандидат фізико-математичних наук, старший науковий співробітник

Інституту кібернетики імені В.М. Глушкова НАН України, Київ.

okhodz@gmail.com

УДК 004.4:519.684

В.Ю. Королёв ${ }^{1}$, А.Н. Ходзинский ${ }^{1^{*}}$

\section{Решение задач комбинаторной оптимизации на квантовых компьютерах}

${ }^{1}$ Институт кибернетики имени В.М. Глушкова НАН Украины, Киев

*Переписка: $\underline{\text { okhodz@gmail.com }}$

Введение. Квантовые компьютеры позволяют получить в несколько раз быстрее решение ряда NPсложных задач комбинаторной оптимизации в сравнении с вычислительными кластерами. Тенденция удвоения количества кубитов квантовых компьютеров каждый год дает основания предполагать существование аналога закономерности Мура для квантовых компьютеров, а это означает, что в ближайшем будущем на них также можно будет получить существенное ускорение решения многих прикладных задач большой размерности.

Цель работы. Обзор способов построения алгоритмов квантовой компьютерной математики для задач комбинаторной оптимизации и анализ влияния особенностей связей между кубитами на выполнение квантовой обработки данных.

Результаты. В работе предложены принципы классификации алгоритмов решения задач с точки зрения квантовой компьютерной математики. Показано, что количество и сила связей между кубитами влияет на размерность задач, решаемых алгоритмами квантовой компьютерной математики. Предложено рассматривать два подхода к вычислению задач комбинаторной оптимизации на квантовых компьютерах: универсальный, с помощью квантовых вентилей, и специализированный, на базе параметризации физических процессов. Приведен пример построения полусумматора для двух кубитов квантового процессора фирмы IBM и пример решения задачи поиска максимального независимого множества для квантовых компьютеров фирм IBM и D-wave.

Выводы. Сегодня квантовые компьютеры доступны онлайн через облачные сервисы для научных исследований и коммерческого использования. На момент написания статьи квантовые процессоры обладают недостаточным количеством кубитов для замены полупроводниковых компьютеров в универсальных вычислениях. Поиск решения задачи комбинаторной оптимизации выполняется с помощью до- 
стижения минимума энергии системы связанных кубитов, на которую отображается задача, а данные являются начальными условиями. Рассмотрены подходы к решению задач комбинаторной оптимизации на квантовых компьютерах и приведены результаты решения задачи поиска максимального независимого множества на квантовых компьютерах фирм IBM и D-wave.

Ключевые слова: квантовый компьютер, квантовая компьютерная математика, кубит, максимальное независимое множество для графа.

MSC 90C27, 68Q12

Vyacheslav Korolyov ${ }^{1}$, Oleksandr Khodzinskyi ${ }^{1}$ *

\title{
Solving Combinatorial Optimization Problems on Quantum Computers
}

\author{
${ }^{1}$ V.M. Glushkov Institute of Cybernetics of the NAS of Ukraine, Kyiv \\ *Correspondence: okhodz@gmail.com
}

Introduction. Quantum computers provide several times faster solutions to several NP-hard combinatorial optimization problems in comparison with computing clusters. The trend of doubling the number of qubits of quantum computers every year suggests the existence of an analog of Moore's law for quantum computers, which means that soon they will also be able to get a significant acceleration of solving many applied largescale problems.

The purpose of the article is to review methods for creating algorithms of quantum computer mathematics for combinatorial optimization problems and to analyze the influence of the qubit-to-qubit coupling and connections strength on the performance of quantum data processing.

Results. The article offers approaches to the classification of algorithms for solving these problems from the perspective of quantum computer mathematics. It is shown that the number and strength of connections between qubits affect the dimensionality of problems solved by algorithms of quantum computer mathematics. It is proposed to consider two approaches to calculating combinatorial optimization problems on quantum computers: universal, using quantum gates, and specialized, based on a parameterization of physical processes. Examples of constructing a half-adder for two qubits of an IBM quantum processor and an example of solving the problem of finding the maximum independent set for the IBM and D-wave quantum computers are given.

Conclusions. Today, quantum computers are available online through cloud services for research and commercial use. At present, quantum processors do not have enough qubits to replace semiconductor computers in universal computing. The search for a solution to a combinatorial optimization problem is performed by achieving the minimum energy of the system of coupled qubits, on which the task is mapped, and the data are the initial conditions. Approaches to solving combinatorial optimization problems on quantum computers are considered and the results of solving the problem of finding the maximum independent set on the IBM and Dwave quantum computers are given.

Keywords: quantum computer, quantum computer mathematics, qubit, maximal independent set for a graph. 